\title{
Lymphocytic Hypophysitis Presenting with Diabetes Insipidus: Case Report and Literature Review
}

\author{
Hiroyuki KOSHIYAMA, Hideki SATO, Sumio YORITA, \\ TOSHIKIYO KOH, TAKAHIRo KANATSUNA*, \\ KazUmasa NISHIMURA**, Katsumi HAYAKAWA**, \\ Jun TAKAHASHI***, AND NoBUo HASHIMOTO*** \\ Divisions of Endocrinology, and *Metabolism, Department of Medicine, \\ **Department of Radiology, Kyoto City Hospital, Kyoto 604, and \\ ***Department of Neurosurgery, Kyoto University Faculty of Medicine, \\ Kyoto 606, Japan
}

\begin{abstract}
Lymphocytic adenohypophysitis is an autoimmune disorder of the anterior pituitary gland which usually occurs in a woman in the postpartum period. It has been considered that lymphocytic hypophysitis is confined to the adenohypophysis sparing the neurohypophysis, and that diabetes insipidus is not a clinical feature of the disorder. Here we report the case of a 50-year-old woman with lymphocytic hypophysitis which presented with diabetes insipidus. MRI indicated homogenous swelling of the whole pituitary gland, loss of the normal high intensity of the posterior pituitary, and thickening of the pituitary stalk. A biopsied specimen of the pituitary revealed diffuse lymphocytic infiltration. The diabetes insipidus was controlled by the administration of DDAVP. The anterior pituitary function was not greatly damaged, and no hormonal replacement therapy was necessary. We suggest that this case represents a variant of lymphocytic adenohypophysitis and/or lymphocytic infundibuloneurohypophysitis, in which the chronic inflammatory process involves the infundibulum, adenohypophysis and neurohypophysis.
\end{abstract}

Key words: Lymphocytic hypophysitis, Diabetes insipidus, Infundibulum, Neurohypophysis.

(Endocrine Journal 41: 93-97, 1994)

LYMPHOCYTIC adenohypophysitis is being reported with increasing frequency as a cause of hypopituitarism, mainly in women during late pregnancy or during the postpartum period [1]. It has been considered that the inflammatory process is confined to the adenohypophysis, sparing the neurohypophysis [1]. Here we report a case of a 50year-old woman with lymphocytic hypophysitis which presented with diabetes insipidus. A review of the pertinent literature is presented, and the possibility of a new syndrome characterized by

\section{Received: July 29, 1993}

Accepted: November 22, 1993

Correspondence to: Dr. Hiroyuki KOSHIYAMA, Division of Endocrinology, Department of Medicine, Kyoto City Hospital, Mibu, Nakagyo-ku, Kyoto 604, Japan lymphocytic infiltration of the adenohypophysis, neurohypophysis and infundibulum is discussed.

\section{Case Report}

A 50-year-old woman had been followed up by one of us (T.K.) for six years because of non-insulin dependent diabetes mellitus. She suddenly developed polydipsia and polyuria up to $6 \mathrm{l} / \mathrm{day}$, although her blood glucose levels were unchanged. She also complained of a headache. Her menstruation was regular. Her urinary and plasma osmolarity was 101 and $285 \mathrm{mOsm} / \mathrm{kg}$ with oral free water intake, respectively. Peak urinary osmolarity after water deprivation was $173 \mathrm{mOsm} / \mathrm{kg}$ and showed a further increase $(522 \mathrm{mOsm} / \mathrm{kg})$ af- 
ter subcutaneous injection of pitressin. The peak plasma antidiuretic hormone (ADH) level, measured by specific radioimmunoassay (RIA), was very low $(0.15 \mathrm{pg} / \mathrm{ml})$, when plasma osmolarity was $296 \mathrm{mOsm} / \mathrm{kg}$. These findings indicated a diagnosis of central complete diabetes insipidus. Magnetic resonance imaging (MRI) showed homogenous swelling of the whole pituitary gland on a T1-weighted image. It also indicated thickening of the pituitary stalk and the absence of a high intensity signal of the neurohypophysis (Fig. 1). Plasma GH and cortisol were measured by specific RIA with commercially available kits, and plasma ACTH, LH, FSH, PRL and TSH levels were determined by immunoradiometric assays. Their levels were normal, except for only slightly increased PRL $(26.8 \mathrm{ng} / \mathrm{ml})$. Provocative tests of anterior pituitary functions revealed that they were not greatly impaired, except for blunted GH response and TSH response to hypoglycemia and to TRH, respectively (Fig. 2). GH showed a normal response to GRF, indicating that the lesion lay in the hypothalamus, including the pituitary stalk, which was in line with the increase in PRL. Serum antipituitary antibodies were measured with rat pituitary cytoplasmic antigens (pituitary cell antibodies; PCA) or pituitary cell surface antigens from $\mathrm{GH}_{3}$ cells and/or AtT-20 cells (pituitary cell surface antibodies; PCSA) [2]. Both PCA and PCSA were negative. The antinuclear factor and

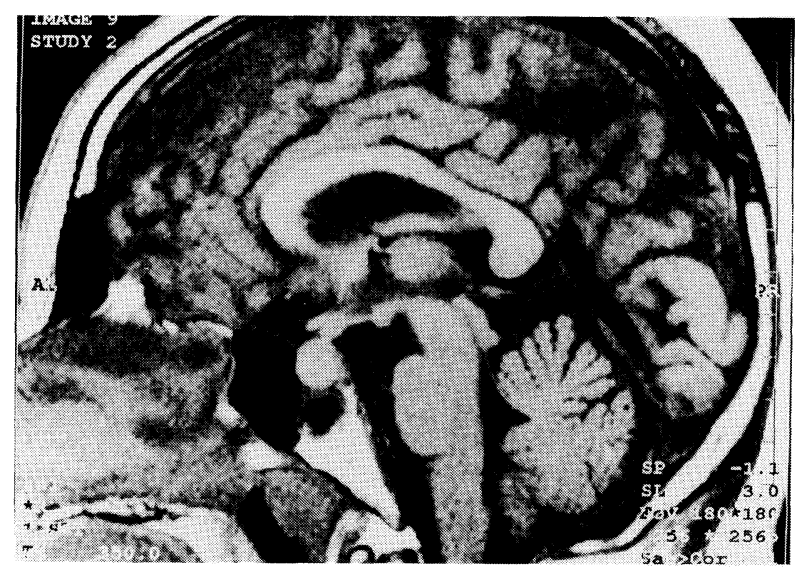

Fig. 1. T1-weighted image of magnetic resonance imaging (MRI). It showed homogenous enlargement of the whole pituitary gland, thickening of the stalk, and absence of a high intensity signal of the posterior lobe. antithyroglobulin and antithyroid microsomal antibodies were also negative, but the rheumatoid factor was positive. Although metastatic carcinoma to the pituitary is frequently seen with diabetes insipidus [3], there was no finding suggesting primary malignancy. Her visual field and visual acuity were normal. The patient was given intranasal DDAVP $(2.5 \mu \mathrm{g} /$ day $)$, but she did not require any other hormone replacement therapy. Biopsy of the sellar lesion was performed through a transsphenoidal approach. The resected specimen revealed diffuse infiltration of mainly mature lymphocytes without any evidence of sarcoidosis, tuberculosis, histiocytosis X, plasmacytoma or giantcell granuloma (Fig. 3). The patient has been followed up only with an oral hypoglycemic agent and DDAVP. Her HLA typing was A2 A9 (A24) B5 (BW52) B16 (B39) CW7 DR2 (DRW8) DQW1 DQW3.

\section{Discussion}

Lymphocytic adenohypophysitis is characterized by chronic inflammation and destruction of the anterior pituitary [4]. It is an autoimmune disorder and frequently associated with Hashimoto's thyroiditis, adrenalitis, ovarian failure, atrophic gastritis and pernicious anemia [1, 4]. Lymphocytic adenohypophysitis is usually accompanied with a headache, visual disturbance and symptoms of hypopituitarism. Diabetes insipidus has not been considered to be a presenting symptom of lymphocytic adenohypophysitis, and none of the 30 patients in a recent review had diabetes insipidus [4]. However, with the increasing recognition of the disorder, four cases of lymphocytic adenohypophysitis associated with diabetes insipidus have been reported very recently in the English literature $[5,6,7]$, in one of which diabetes insipidus was transient [5]. Table 1 summarizes the reported cases of lymphocytic adenohypophysitis presenting with diabetes insipidus. Three of the cases were female patients whose age ranged from 34 to 49 years. An MRI study was performed in only one of the cases, which showed diffuse pituitary enlargement and infundibular thickening [7], as in the present case.

The pathogenesis of diabetes insipidus in these cases with lymphocytic adenohypophysitis may 

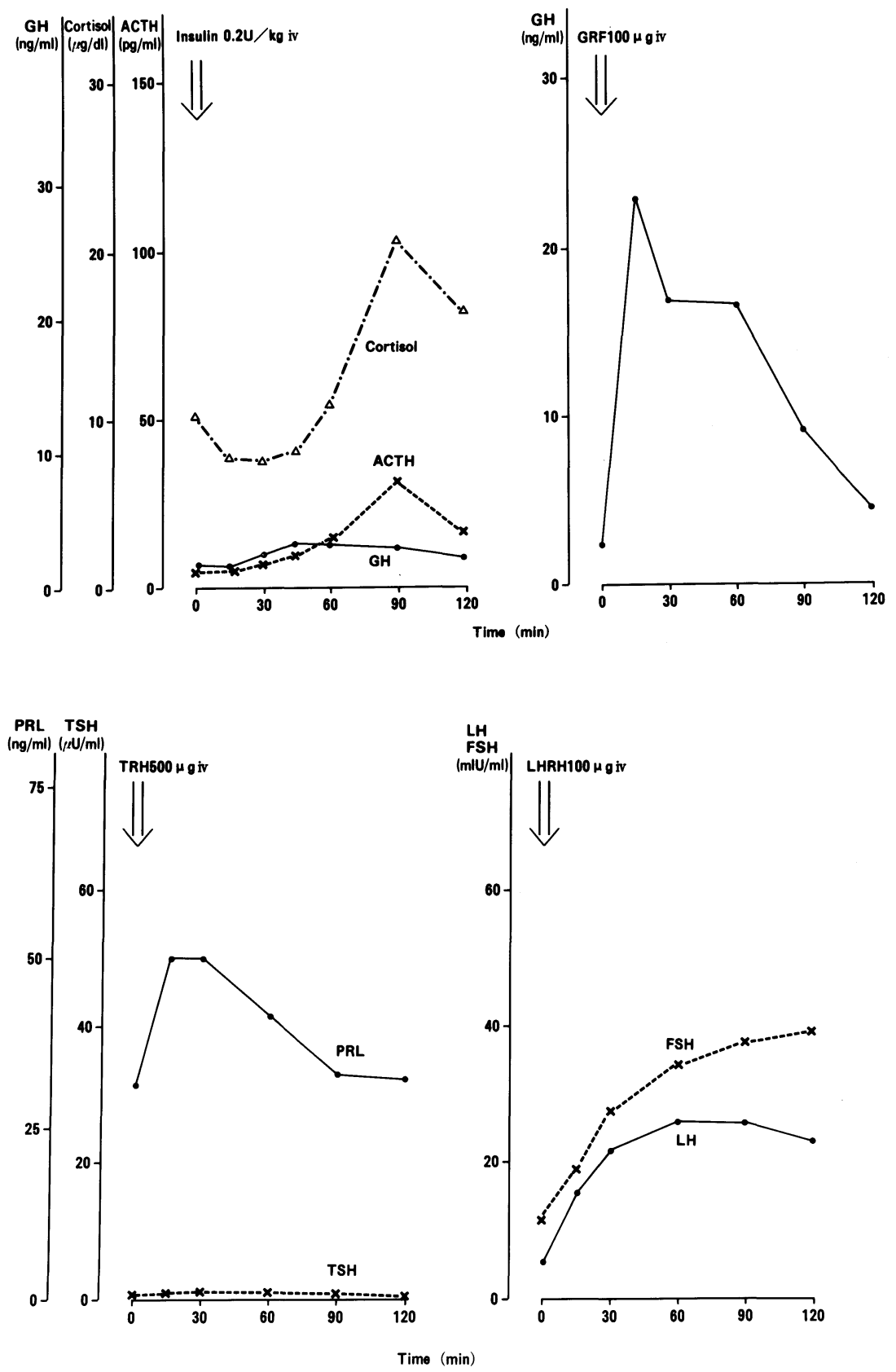

Fig. 2. Provocative tests of anterior pituitary functions. Insulin $(0.2 \mathrm{U} / \mathrm{kg}), \mathrm{GRF}$, TRH and LHRH were injected intravenously as a bolus injection.

possibly be explained in one of the following two ways: First, the neurohypophysis or hypothalamus may be compressed by a mass in the adenohypophysis, causing a decrease in ADH secretion, as suggested in a recently reported case [7]. However, that possibility seems remote in this case, consider- ing that the mass was without suprasellar extension. Second, an autoimmune process may not be restricted to the adenohypophysis only, as hitherto recognized, but may also involve the neurohypophysis and pituitary stalk. It was earlier reported that a case with diabetes insipidus revealed 


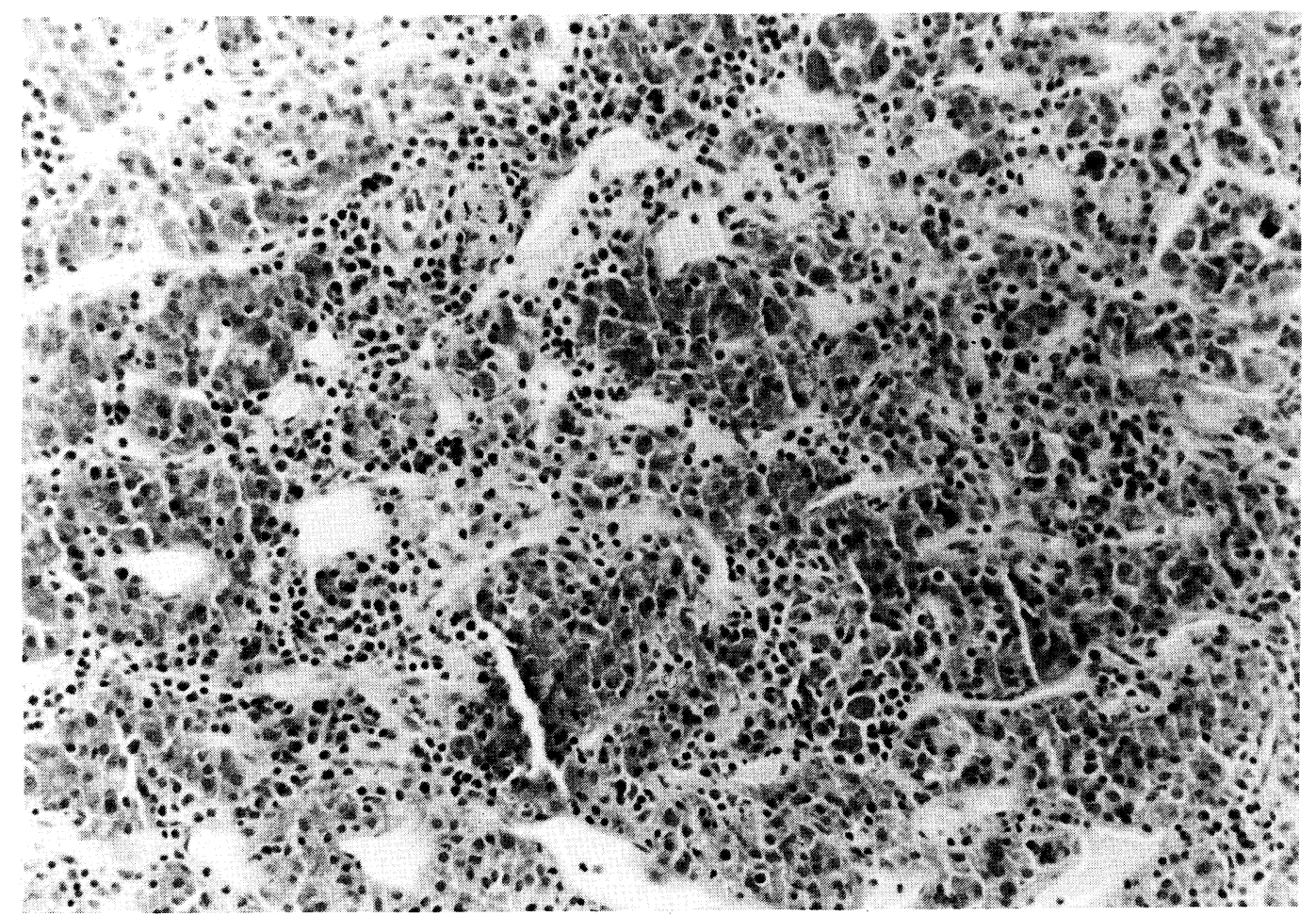

Fig. 3. A photomicrograph of the pituitary specimen biopsied (hematoxylin-eosin; original magnification $\times 200$ ). It shows remarkable infiltration mainly of lymphocytes and a small number of plasma cells.

Table 1. Summary of cases of lymphocytic adenohypophysitis presenting with diabetic insipidus

\begin{tabular}{|c|c|c|c|c|}
\hline Authors & Age & Sex & $\begin{array}{l}\text { Anterior pituitary } \\
\text { dysfunctions* }\end{array}$ & Other symptoms \\
\hline Vanneste et al.[5] & 49 & $\mathrm{~F}$ & TSH, PRL, ACTH & headache, fatigue, galactorrhea \\
\hline McDermott et al.[6] & 45 & $\mathrm{~F}$ & $\begin{array}{l}\text { TSH, ACTH, GH } \\
\text { LH, FSH, PRL }\end{array}$ & $\begin{array}{l}\text { visual disturbance } \\
\text { fatigue, decreased libido }\end{array}$ \\
\hline Nussbaum et al.[7] & 40 & M & ACTH & $\begin{array}{l}\text { visual disturbance } \\
\text { headache, fatigue, impotence }\end{array}$ \\
\hline Nussbaum et al.[7] & 34 & $\mathrm{~F}$ & PRL & amenorrhea, headache \\
\hline The present case & 50 & $\mathrm{~F}$ & TSH, PRL, (GH) & headache \\
\hline
\end{tabular}

*Anterior pituirary hormones were described of which the basal levels were low (except for that of PRL, which was high), and/or showed low response to provocative tests.

chronic inflammation of the neurohypophysis [8]. Imura et al. have very recently indicated that lymphocytic infundibulo-neurohypophysitis is a common cause of central diabetes insipidus [9]. It showed characteristic MRI findings, such as thickening of the infundibulum and/or pituitary stalk and the absence of a high intensity signal of the neurohypophysis, as in the present case [9]. An- other group has reported two cases presenting with hypopituitarism and diabetes insipidus with histological findings of pituitary necrosis [10]. They propose that they be called "necrotizing infundibulo-hypophysitis". The present case differs from lymphocytic infundibulo-neurohypophysitis: it was not confined to the infundibulum and posterior pituitary, but involved the anterior 
pituitary, showing enlargement of the whole pituitary gland as well as thickening of the pituitary stalk. It was also different from "necrotizing infundibulo-hypophysitis" [10] in its histological findings, although it shared clinical and MRI findings with them. Taken together, it appears that the present case is a variant of lymphocytic infundibulo-neurohypophysitis and/or lymphocytic adenohypophysitis which involves the adenohypophysis as well as the infundibulum and neurohypophysis. In this context, it is to be noted that a case with lymphocytic hypophysitis which originated in the infundibular stalk has been reported [1]. It is also possible that "necrotizing infundibulo-hypophysitis" proposed by Ahmed et al. [10] may represent an end-stage condition of such a disorder. Although the term lymphocytic adenohypophysitis has been interchangeably used with that of lymphocytic hypophysitis [5, 11], the latter may be misleading considering these possibilities. It has been of interest whether steroid therapy may have beneficial effects on the clinical course of lymphocytic hypophysitis, probably depending on its stage $[4,11]$. The steroid therapy has not been tried in our case because of the coexisting diabetes mellitus.

In summary we report a case with diabetes insipidus and a mild degree of hypopituitarism with characteristic MRI findings of pituitary enlargement, swelling of the pituitary stalk, and the absence of a high signal of the neurohypophysis. Its histology showed lymphocytic infiltration of the pituitary. We suggest that this case represents a variant of lymphocytic adenohypophysitis and/or lymphocytic infundibulo-neurohypophysitis.

\section{References}

1. Pestell RG, Best JD, Alford FP (1990) Lymphocytic hypophysitis: the clinical spectrum of the disorder and evidence for an autoimmune pathogenesis. Clin Endocrinol 33: 457-466.

2. Kajita K. Yasuda K, Yamakita N, Murai T, Matsuda M, Mori A, Murayama M, Tanahashi S, Sugiura M, Miura K (1991) Anti-pituitary antibodies in patients with hypopituitarism and their families: longitudinal observation. Endocrinol Japon 38: 121-129.

3. Koshiyama H, Ohgaki K, Hida S, Takasu K, Yumitori K, Shimatsu A, Koh T (1992) Metastatic renal cell carcinoma to the pituitary gland presenting with hypopituitarism. J Endocrinol Invest 15: 677-681.

4. Cosman F, Post KD, Holub DA. Wardlaw SL (1989) Lymphocytic hypophysitis. Report of 3 new cases and review of the literature. Medicine 68: 240-256.

5. Vanneste JAL, Kamphorst W (1987) Lymphocytic hypophysitis. Surg Neurol 28: 146-149.

6. McDermott MW, Grisdale DE, Berry K, Wilkins GE (1988) Lymphocytic adenohypophysitis. Can J Neurol Sci 15: 38-43.
7. Nussbaum CE, Okawara S-H, Jacobs LS (1991) Lymphocytic hypophysitis with involvement of the cavernous sinus and hypothalamus. Neurosurgery 28: $440-444$.

8. Saito T, Yoshida S, Nakao K, Takanashi R (1970) Chronic hypernatremia associated with inflammation of the neurohypophysis. J Endocr 31: 391-396.

9. Imura $H$, Nakao $K$, Shimatsu A, Ogawa $Y$, Sano $T$, Fujisawa I, Yamabe H (1993) Lymphocytic infundibuloneurohypophysitis as a cause of central diabetes insipidus. New Engl J Med 329: 683-689.

10. Ahmed SR, Aiello DP, Page R, Hopper $K$, Towfighi J, Santen RJ (1993) Necrotizing infundibulohypophysitis: a unique syndrome of diabetes insipidus and hypopituitarism. J Clin Endocrinol Metab 76: 1499-1504.

11. Reusch J E-B, Kleinschmidt-Demasters KB, Lillehei KO, Rappe D, Gutierrez-Hartman A (1992) Preoperative diagnosis of lymphocytic hypophysitis (adenohypophysitis) unresponsive to short course dexamethasone: case report. Neurosurgery 30: 268-272. 